\title{
EXPERIMENTAL INVESTIGATION OF PARAFFIN-BASED FUELS FOR HYBRID ROCKET PROPULSION
}

\author{
L. Galfetti, L. Merotto, M. Boiocchi, F. Maggi, \\ and L. T. DeLuca
}

\author{
Politecnico di Milano, Aerospace Engineering Department \\ Space Propulsion Laboratory (SPLab) \\ 34 via La Masa, Milano, MI I-20156, Italy
}

Solid fuels for hybrid rockets were characterized in the framework of a research project aimed to develop a new generation of solid fuels, combining at the same time good mechanical and ballistic properties. Original techniques were implemented in order to improve paraffin-based fuels. The first strengthening technique involves the use of a polyurethane foam (PUF); a second technique is based on thermoplastic polymers mixed at molecular level with the paraffin binder. A ballistic characterization of paraffin-based hybrid rocket solid fuels was performed, considering pure wax-based fuels and fuels doped with suitable metal additives. Nano-Al powders and metal hydrides (magnesium hydride $\left(\mathrm{MgH}_{2}\right)$, lithium aluminum hydride $\left(\mathrm{LiAlH}_{4}\right)$ ) were used as fillers in paraffin matrices. The results of this investigation show a strong correlation between the measured viscosity of the melted paraffin layer and the regression rate: a decrease of viscosity increases the regression rate. This trend is due to the increasing development of entrainment phenomena, which strongly increase the regression rate. Addition of $\mathrm{LiAlH}_{4}$ (mass fraction 10\%) can further increase the regression rate up to $378 \%$ with respect to the pure HTPB regression rate, taken as baseline reference fuel. The highest regression rates were found for the Solid Wax (SW) composition, added with $5 \% \mathrm{MgH}_{2}$ mass fraction; at $350 \mathrm{~kg} /\left(\mathrm{m}^{2} \mathrm{~s}\right)$ oxygen mass flux, the measured regression rate, averaged in space and time, was $2.5 \mathrm{~mm} / \mathrm{s}$, which is approximately five times higher than that of the pure HTPB composition. Compositions added with nanosized aluminum powders were compared with those added with $\mathrm{MgH}_{2}$, using gel or solid wax. 


\section{NOMENCLATURE}

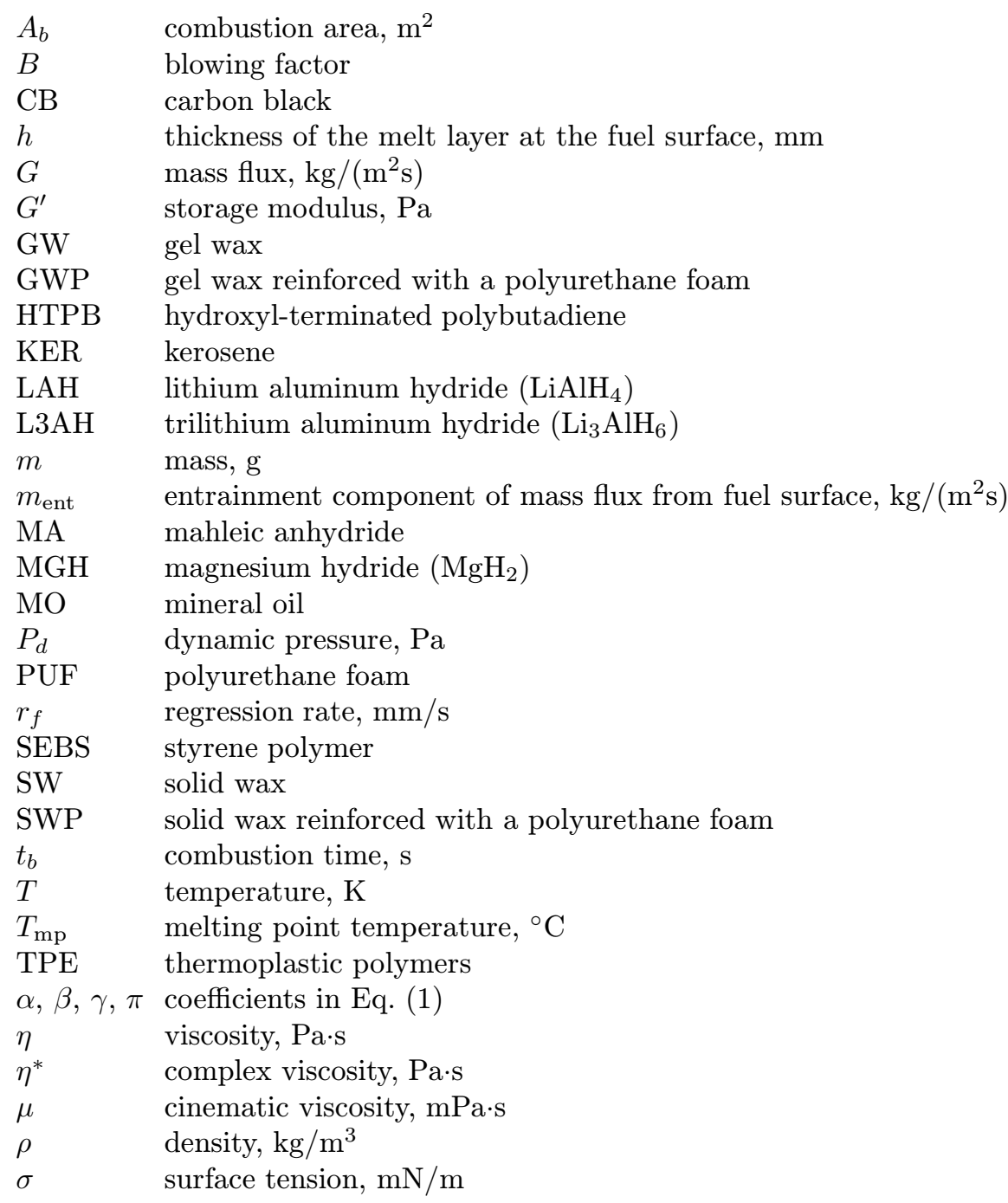

\section{INTRODUCTION}

The first privately funded manned-space flights of the SpaceShip family demonstrate the advantages of hybrid rocket technology: safety, cost, simplicity, and 
performance. These flights have advanced the maturity of hybrid technology and show the possibilities of hybrid rockets in future applications, manned and unmanned.

The choice of an $\mathrm{N}_{2} \mathrm{O}-\mathrm{HTPB}$ system, due to the high vapor pressure of $\mathrm{N}_{2} \mathrm{O}$, which allows the system to be self-pressurizing, leading to a blowdown solution, greatly simplifies the SpaceShipOne propulsion system design. The drawback is a relatively low regression rate, unacceptable for other mission requirements. The need to obtain much higher regression rates is well known and research activities are widely carried out in several laboratories all over the world.

The solid fuel regression rate, which is the key variable for the overall hybrid motor design, is affected by turbulent and radiant heat transfer, gas-phase kinetics and, eventually, heterogeneous reactions occurring at the solid fuel surface, grain geometry, pressure, oxidizer injection process, axial or radial, including swirl injection configurations. All these effects were largely investigated in order to increase the regression rate $[1,2]$.

The effects of fuel additives for enhancing regression rates were considered by several researchers. Metal additives can raise the theoretical flame temperature, produce a strong radiation from the metal oxide combustion products, reduce the fuel gasification heat, reduce the blocking effect of the pyrolyzed mass blowing (only gaseous products shield the solid fuel surface from convective heat transfer to the surface itself); these effects can determine high fuel regression rates $[3-5]$. However, they are not attractive if they are not supported by a high combustion efficiency and also the fuel mechanical properties have to be carefully tested.

Liquefied solid fuels were proposed by Karabeyoglu and other researchers [610]; regression rates are usually much faster than those of traditional hybrid fuels, because of the fuel surface melting and the following droplet entrainment process.

The purpose of this paper is to discuss the most recent results obtained at the Space Propulsion Laboratory (SPLab) of Politecnico di Milano concerning the development and characterization of paraffin-based solid fuels for hybrid propulsion.

Fuel characterization was carried out in terms of ballistic characterization (average regression rate measurement). The tests were performed using gel and solid wax, in pure or doped compositions. Nano-Al powders and metal hydrides, simple as $\mathrm{MgH}_{2}$ or double as $\mathrm{LiAlH}_{4}$, were used as fillers in the paraffin matrix. An original approach, which resorts to a polyurethane foam (PUF) used as a strengthening structure for the paraffin matrix, was investigated and implemented to assure mechanical properties good enough to consider the use of a paraffin-based fuel in a real hybrid motor. The regression rate was measured vs. the oxidizer mass flux (gaseous oxygen) in a range from $100 \mathrm{up}$ to $350 \mathrm{~kg} /\left(\mathrm{m}^{2} \mathrm{~s}\right)$, in a slab experimental device developed at SPLab. 


\section{FUEL FORMULATIONS AND EXPERIMENTAL METHODS}

The average regression rate $r_{f}$ of the fuel formulations tested was measured performing some firing tests in a two-dimensional (2D) slab hybrid burner, designed and set up at SPLab and shown in Fig. 1. The chamber is equipped with an oxygen (oxidizer) and a nitrogen (used for a quick extinction of the oxidation reactions after the oxygen shut off) inlet system. A calibrated nozzle for the mass flow measurement, a piezoelectric pressure transducer, a pyrotechnic ignition device, check valves, and relief valves complete the $2 \mathrm{D}$ slab burner device. The fuel slabs have the size $50 \times 10 \times 4 \mathrm{~mm}$; the sample holders designed for this work are shown in Fig. 2, with the fuel slabs drawn in dark color. Double slab configuration is used for the firing tests presented in this work.

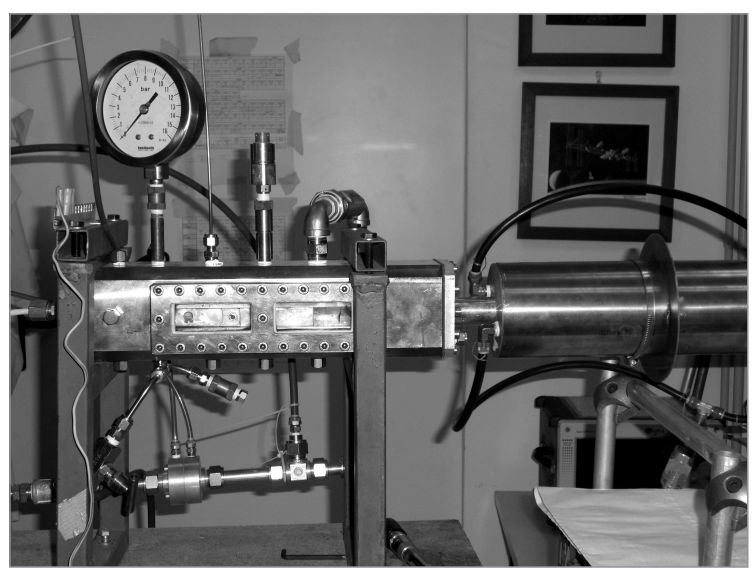

Figure 1 Two-dimensional slab burner

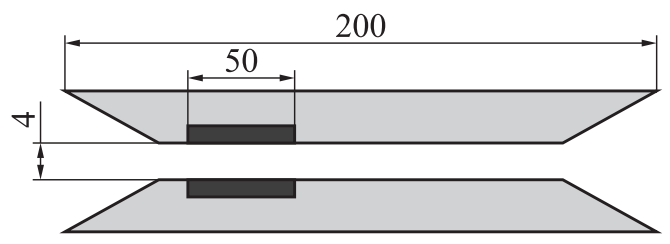

Figure 2 Sample holders designed for this work. The fuel slabs are drawn in dark color. Dimensions are in millimeters 
The average regression rate $\left(r_{f}\right)$ is measured from the burned mass $(\Delta m)$, the fuel density $\left(\rho_{f}\right)$, the burning time $\left(t_{b}\right)$ and the burning area $\left(A_{b}\right)$, using the following equation:

$$
r_{f}=\frac{\Delta m}{\rho_{f} t_{b} A_{b}} .
$$

The fuel formulations manufactured and tested include a group based on HTPB (H-), a group based on gel wax (GW-), and a group based on solid wax $(\mathrm{SW}-)$. The selected paraffin waxes (GW and SW) have chemical formulas $\mathrm{C}_{12} \mathrm{H}_{26}$ and $\mathrm{C}_{24} \mathrm{H}_{50}$, respectively. Several other formulations were obtained through additive filling. The GW- and SW-based fuels were added with nanoAluminum powders (Alex50 and Alex100, with average particle size of 50 and $100 \mathrm{~nm}$, respectively), with an $\mathrm{MgH}_{2}$ powder (particle size in the range 50$150 \mu \mathrm{m}$ ), or with LAH or L3AH. A fourth group of fuel formulations based on GW, PUF, and KER was prepared (GWPK-). Kerosene was added in order to reduce the fuel formulation viscosity, which is expected to influence the entrainment phenomenon and, thus, the overall regression rate. A fifth group is based on SEBS and LP, filled with SW, mineral oil (MO), and/or KER.

A significant aspect of this work is represented by the role played by the paraffin matrix strengthening technique, based on the use of PUFs, implemented in order to ensure good mechanical properties for paraffin-based fuels. This technique allows obtaining high overall regression rate values, even in lab-scale facilities $[11,12]$.

First, the strengthening with a PUF structure was investigated. These materials are obtained by pouring a melted paraffin within a sponge's pores. Synthetic cellular solids in the form of the structural honeycombs and in the form of foams have been used for many applications such as lightweight structural elements, filters, and insulators. The term 'cell foams' indicates materials composed by a number of cells, i. e., cavities containing gas, delimited by edges and eventually by solid faces. Polymeric materials become a polymeric foam via an expansion process. This process consists in gas bubbles generating in a melt polymer (if thermoplastic) or in a prepolymer (if thermosetting); then bubbles are expanded and finally the growing is stuck by a cooling process (thermoplastic polymer) or by a curing process (thermosetting polymer). The cell characteristic size is in the range $300-400 \mu \mathrm{m}$, while the PUF density is $0.02 \mathrm{~g} / \mathrm{cm}^{3}$. The PUF structure leads to a notable increase in the regression rate, but results in heterogeneous fuels, thus in nonisotropic mechanical properties. Figure 3 shows the PUF structure in the mould used for melted paraffin pouring in the reinforcing structure.

A second type of strengthening structure involving thermoplastic polymers (TPE) soluble in paraffin (SEBS-MA) was then designed and tested, with the aim to increase the paraffin elasticity without any decrease in the regression rate value and ensuring isotropic mechanical properties. Thermoplastic polymers such as SEBS (Styrene-Etylene-Butylene-Styrene terpolymer) and SIS 


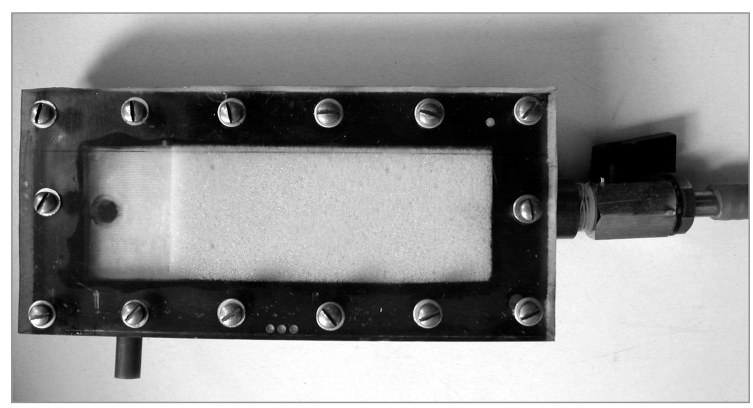

Figure 3 Sample mould and PUF strengthening structure for paraffin-based fuel formulations

(Styrene-Isoprene-Styrene copolymer) mix with the paraffin at molecular level. The mixing procedure developed in this work is obtained following three steps: the first involves a solubilization of the polymers in volatile solvent (cyclohexane); then, the swelled polymer is mixed with the correct amount of paraffin (liquid or solid); and finally, the volatile solvent evaporation is carried out. The procedure does not involve a simple heating of the pure polymers in order to avoid their thermal degradation (the pure polymers have melting temperature of about $180{ }^{\circ} \mathrm{C}$ ). In order to tailor the melting temperature and viscosity of the melted compound obtained, several ingredients having a different aromatic content were used. The use of TPE reinforcing structure in paraffin results in lower manufacturing costs and in homogeneous fuels. Moreover, the GW-PUF formulation melting point temperature and viscosity decrease through additive

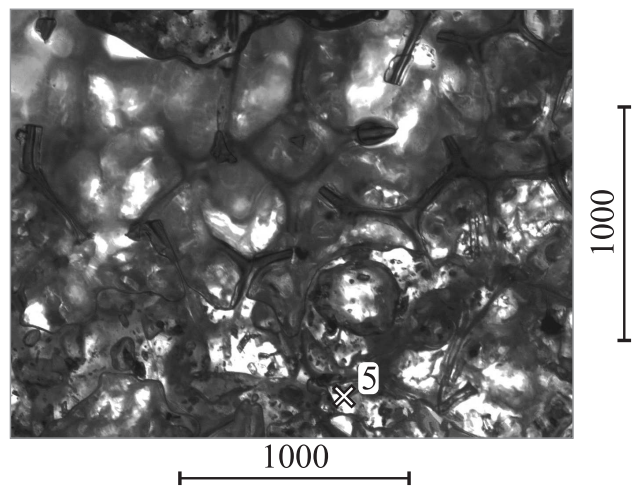

Figure 4 Polimeric open-cell foam soaked with paraffin gel and LAH (97\%-3\%). Dimensions are in microns 
Table 1 Fuel formulations manufactured and tested. Composition and theoretical density

\begin{tabular}{|c|c|c|c|}
\hline $\begin{array}{c}\text { Fuel } \\
\text { formulations }\end{array}$ & Ingredients & & $\begin{array}{c}\text { Fuel } \\
\text { density, } \\
\mathrm{g} / \mathrm{cm}^{3}\end{array}$ \\
\hline$\overline{\mathrm{HTPB}}$ & HTPB $100 \%$ & - & 0.92 \\
\hline H-MGH5 & НTPB $95 \%$ & MGH $5 \%$ & \\
\hline GW & GW $100 \%$ & - & 0.88 \\
\hline GW & PUF $3 \%+$ GW $97 \%$ & - & 0.88 \\
\hline GW-LAH3 & PUF $3 \%+$ GW $94 \%$ & LAH $3 \%$ & 0.88 \\
\hline GW-MGH5 & PUF $3 \%+$ GW $92 \%$ & MGH 5\% & 0.87 \\
\hline GW-Alex100-5 & PUF $3 \%+$ GW $92 \%$ & Alex100 5\% & 0.87 \\
\hline GWK & PUF $3 \%+$ GW $87.3 \%+$ KER $9.7 \%$ & - & 0.87 \\
\hline GWK-MGH3 & PUF $3 \%+$ GW $84.6 \%+$ KER $9.4 \%$ & MGH $3 \%$ & 0.88 \\
\hline GWK-L3AH3 & PUF $3 \%+$ GW $84.6 \%+$ KER $9.4 \%$ & $\mathrm{Li}_{3} \mathrm{AlH}_{6} 3 \%$ & 0.87 \\
\hline GWK-LAH10 & PUF $3 \%+$ GW $78.3 \%+$ KER $8.7 \%$ & LAH $10 \%$ & 0.88 \\
\hline SW & SW $100 \%$ & - & 0.89 \\
\hline SW & PUF $3 \%+$ SW $97 \%$ & - & 0.88 \\
\hline SW-CB0.2 & SW $99.8 \%$ & CB $0.2 \%$ & 0.87 \\
\hline SW-Alex100-5 & PUF $3 \%+$ SW $92 \%$ & Alex100 5\% & 0.87 \\
\hline SW-Alex50-5 & PUF $3 \%+$ SW $92 \%$ & Alex50 5\% & 0.87 \\
\hline SW-MGH5 & PUF $3 \%+$ SW $92 \%$ & MGH 5\% & 0.87 \\
\hline SW-LAH3 & PUF $3 \%+$ SW $94 \%$ & LAH $3 \%$ & 0.88 \\
\hline SW-LAH6 & PUF $3 \%+$ SW $91 \%$ & LAH $6 \%$ & 0.88 \\
\hline SW-LAH10 & PUF $3 \%+$ SW $87 \%$ & LAH $10 \%$ & 0.88 \\
\hline SEBS-MO-SW-KER & SEBS $15 \%+$ MO $25 \%$ & SW $50 \%+$ KER $10 \%$ & 0.90 \\
\hline
\end{tabular}

Table 2 Physical properties of paraffins

\begin{tabular}{ccccc}
\hline \multirow{2}{*}{$\begin{array}{c}\text { Paraffin } \\
\text { type }\end{array}$} & $\begin{array}{c}\text { Chemical } \\
\text { formula }\end{array}$ & $\begin{array}{c}\text { Density, } \\
\mathrm{g} / \mathrm{cm}^{3}\end{array}$ & $\begin{array}{c}\text { Measured } \\
\text { viscosity } \\
\text { at } T=333 \mathrm{~K},\end{array}$ & $\begin{array}{c}\text { Measured } \\
\text { viscosity } \\
\text { at } T=343 \mathrm{~K}, \mathrm{~s}\end{array}$ \\
\hline Gel wax $(\mathrm{GW})$ & $\mathrm{C}_{12} \mathrm{H}_{26}$ & 0.88 & 11.29 & $\mathrm{~Pa} \cdot \mathrm{s}$ \\
Solid wax (SW) & $\mathrm{C}_{24} \mathrm{H}_{50}$ & 0.89 & 0.89 & 1.12 \\
\hline
\end{tabular}

(kerosene) inclusion was investigated, with the aim to increase the fuel regression rate up to values similar to those typical of SW-PUF formulation. A microscope picture of the formulation obtained adding a 3 percent mass fraction of PUF in paraffin doped with LAH is shown in Fig. 4.

Fuel nomenclature, composition, and density are presented in Tables 1-3. Among the SEBS-containing formulations, only the most promising formulation from the mechanical properties point of view (SEBS-MO-SW-KER) was tested 
Table 3 Physical properties of energetic powders

\begin{tabular}{ll}
\hline \multicolumn{1}{c}{ Energetic powder } & \multicolumn{1}{c}{ Description } \\
\hline \multirow{2}{*}{$\mathrm{MgH}_{2}$} & Supplied by ABCR (Germany). Purity 98\%; de- \\
& composition temperature: $553 \mathrm{~K}$; hydrogen con- \\
& tent $7.65 \%$. Size in the range $50-150 \mu \mathrm{m}$ \\
\hline & Supplied by SibTermoChim (Russia). Uncoated \\
& powders with nominal particle size 0.05 and \\
& $0.10 \mu \mathrm{m}$ (specific surface area 24.5 and $15.5 \mathrm{~m}^{2} / \mathrm{g}$, \\
& respectively) \\
\hline $\mathrm{LiAlH}_{4}$ & Supplied by Sigma Aldrich (Germany). Size \\
& about $100 \mu \mathrm{m}$ \\
\hline
\end{tabular}

for the $r_{f}$ measurement. Ballistic results will be presented in detail in the following section.

\section{RESULTS AND DISCUSSION}

Firing tests were performed and the average regression rates of different fuel formulations were compared. For each test, the operating pressure is $1.5 \mathrm{bar}$, the oxidizer is pure gaseous oxygen and the oxygen mass flux ranges from 100 to $350 \mathrm{~kg} / \mathrm{m}^{2} \mathrm{~s}$. The results of the firing tests performed are reported in Figs. 5-8, in which the measured regression rate is plotted vs. the oxygen mass flux $\left(G_{\text {ox }}\right)$.

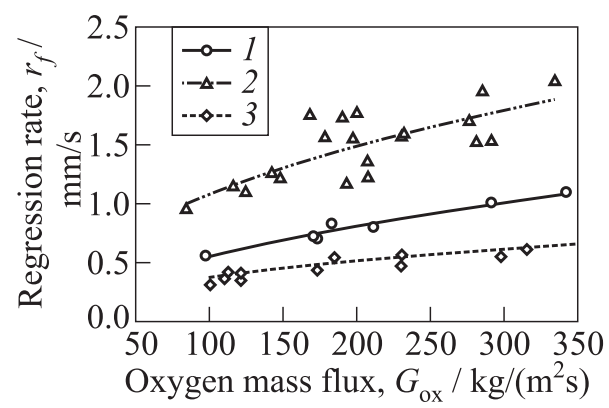

Figure 5 Regression rate vs. oxygen mass flux for nonfilled fuel formulations: GW (1) and SW (2) are compared to HTPB (3) taken as reference. Operating pressure 1.5 bar

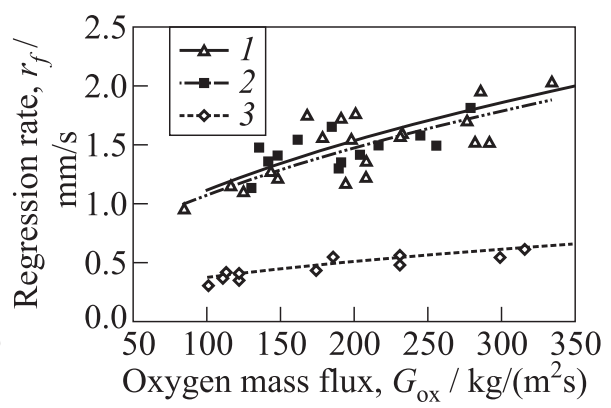

Figure 6 Regression rate vs. oxygen mass flux for SW (1) and SW filled with $0.2 \%$ CB (2) compared to HTPB (3). Operating pressure 1.5 bar 


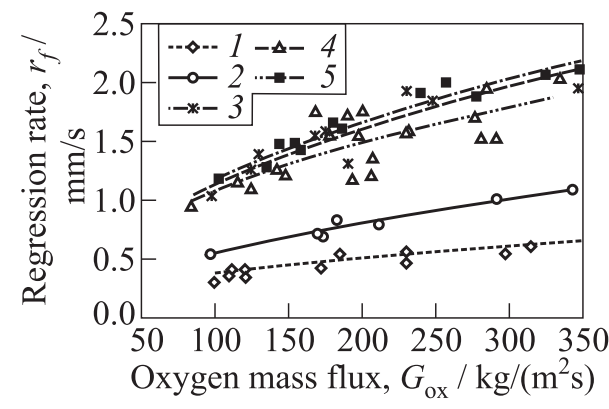

$\begin{array}{lll}\text { Figure } & 7 & \text { Regression rate vs. oxygen }\end{array}$ mass flux for fuel formulations filled with $n$-Al powder (Alex100): $1-\mathrm{HTPB} ; 2-$ GW; 3 - GW-Alex 100-5; 4 - SW; and 5 - SW-Alex 100-5. Operating pressure $1.5 \mathrm{bar}$

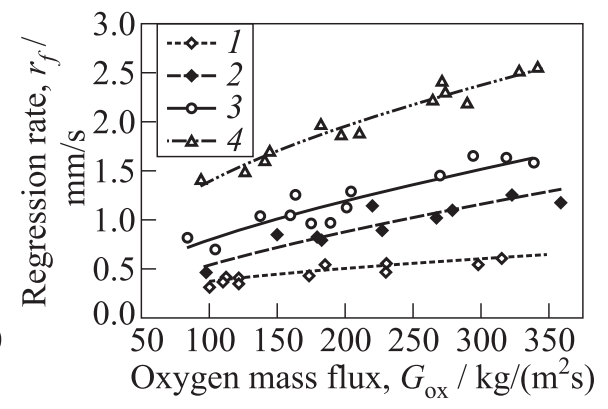

Figure 8 Regression rate vs. oxygen mass flux for fuel formulations filled with $\mathrm{MgH}_{2}: 1-\mathrm{HTPB} ; 2-\mathrm{H}-\mathrm{MGH} 5 ; 3-$ GW-MGH5; and 4 - SW-MGH5. Operating pressure 1.5 bar.

Table 4 Coefficients obtained for the $r_{f} / G_{\text {ox }}$ curves and $r_{f}$ percentage increase with respect to reference formulation, for all the tested fuels

\begin{tabular}{lccc}
\hline \multicolumn{1}{c}{$\begin{array}{c}\text { Fuel } \\
\text { formulation }\end{array}$} & \multicolumn{2}{c}{$r_{f}=a\left(G_{\text {ox }}\right)^{n}$} & $r_{f}$ variation \\
\cline { 2 - 3 } vs. HTPB, $\%$
\end{tabular}


The results for the nonfilled fuel formulations are shown in Fig. 5. Pure HTPB regression rate is about $0.6 \mathrm{~mm}$ at the highest oxygen mass fluxes tested $\left(350 \mathrm{~kg} /\left(\mathrm{m}^{2} \mathrm{~s}\right)\right)$. At the same oxygen mass fluxes, GW and $\mathrm{SW}$ give a regression rate of about 1.1 and $2 \mathrm{~mm} / \mathrm{s}$, respectively. For each fuel formulation, the $r_{f}$ curve vs. $G_{\text {ox }}$ is obtained and reported in Table 4 .

A comparison between the results obtained for SW and SW filled with $0.2 \%$ carbon black $(\mathrm{CB})$ is shown in Fig. 6. Addition of $\mathrm{CB}$ does not significantly change SW performance, due to the low mass added.

Regression rate results for $\mathrm{GW}$ and $\mathrm{SW}$ fuel formulations added with $n$-Al and with $\mathrm{MgH}_{2}$ hydride are shown in Figs. 7 and 8, respectively, in which $r_{f}$ vs. $G_{\text {ox }}$ curves are reported.

The comparison among metalized and nonmetalized fuel formulations shows that the $n$-Al addition results in a regression rate increase for both $\mathrm{GW}$ and $\mathrm{SW}$ fuels. At the highest oxygen mass flux tested, n-Al addition to GW fuel leads to a regression rate increase of about $71 \%$, with respect to the nonfilled formulations while for SW, the increase is only $17 \%$. When $\mathrm{MgH}_{2}$ is added, the percentage $r_{f}$ increase with respect to pure $\mathrm{GW}$ and $\mathrm{SW}$ is similar $(25 \%$ and $38 \%$, respectively, at the highest oxygen mass fluxes tested), thus suggesting that the powder addition has a different effect depending on the binder.

Results obtained for SW doped

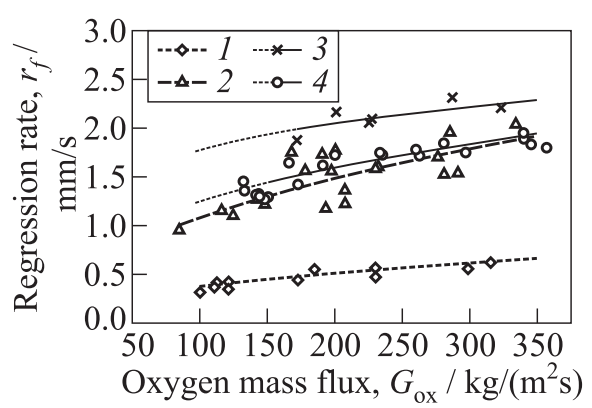

Figure 9 Regression rate vs. oxygen mass flux for fuel formulations filled with LAH: 1 - HTPB; 2 - SW; 3 - SW-LAH3; and 4 - SW-LAH6. Operating pressure 1.5 bar with different amounts of LAH are shown in Fig. 9. Tests were also performed with HTPB-based fuels filled with LAH, but unlike SW-based fuels, HTPB-LAH formulations display a reduced regression rate with respect to pure HTPB. The reason of this different behavior is due to lithium different combustion mechanism in different binders. In HTPB binder, lithium reacts with polymer fragments during HTPB combustion, inducing a phenomenon similar to repolymerization. This phenomenon results in a reduced gasification, and thus in a reduced regression rate. The formation of carbon structures on the sample surface confirms this interpretation, because such structures are associated to molecular recombination reactions. This phenomenon does not occur when SW is the fuel binder; therefore, in SW-based fuels, LAH addition results in an enhanced overall regression rate due to the high hydrogen content.

The obtained $r_{f}$ vs. $G_{\text {ox }}$ curves for SW-based fuels are shown in Fig. 9. It can be observed that $3 \% \mathrm{LAH}$ addition leads to very small performance increase 
with respect to pure SW ( $+6 \%$ at the highest oxygen mass flux tested). An addition of $6 \% \mathrm{LAH}$ leads to higher regression rate enhancement $(+26 \%$ with respect to SW, at the highest oxygen mass flux tested).

The regression rate vs. oxygen mass flux curves were obtained for all the tested fuel formulations, assuming a power law:

$$
r_{f}=a G^{n} .
$$

Increasing the distance from the head end of the fuel grain, the fuel accumulation and the increase in turbulence intensity, with a corresponding increase in heat transfer to the fuel surface, cause a regression rate increase in the downstream direction. This trend, which is confirmed by several experimental regression rate results, under the operating conditions of the investigation performed in this work is strongly mitigated by the sample size. Likewise, the regression rate usually decreases with time due to the port area increase, which determines a corresponding decrease in the port mass flux. But combustion times are very short in this investigation, thus allowing to neglect also this dependence. Sometimes, regression rate correlations, proposed for hybrids, include the boundary layer-blowing parameter, usually named $B$, which can be defined as the ratio between the core flow thermal energy (per unit mass) and the fuel gasification thermal energy (per unit mass), required at the fuel surface in order to sustain the solid to gas fuel transition. As noted by Marxman, $B$ is raised to a small power, allowing to express the fuel regression rate dependence primarily on $G$, which in this work is considered as the oxidizer mass flux.

Table 4 reports the coefficients obtained for the regression rate vs. oxygen mass flux curves. It can be observed that pure HTPB displays one of the lowest exponents $(n=0.44)$. Similar values of the exponent are obtained for the other formulations, with $n$ in the range $0.45-0.55$. This leads to the conclusion that all the tested formulations tend to display a similar rate of $r_{f}$ increase with increasing oxygen mass flux. Similar results for the exponent $n$ are reported in the open literature [2]. Lower exponents $(n=0.2-0.35)$ are obtained for LAHfilled formulations when the additive mass fraction is low $(3 \%$ and $6 \%)$, thus suggesting this kind of fuel displays a lower rate of enhancement with increasing oxidizer mass flux. A different trend was observed when LAH mass fraction is increased up to $10 \%$ (see Table 4).

The average regression rate of the tested fuel formulations was measured at a reference condition, corresponding to $150 \mathrm{~kg} /\left(\mathrm{m}^{2} \mathrm{~s}\right)$ oxidizer mass flux and 1.5-bar operating pressure. The tests were performed in double slab configuration, with pure oxygen as oxidizer. The results of the ballistic characterization are shown in Figs. $10 a$ (regression rates) and $10 b$ (percentage increase), where a selection of the investigated formulations are compared to the reference formulation (pure HTPB). Regression rate percentage increase compared to pure HTPB, estimated at $150 \mathrm{~kg} /\left(\mathrm{m}^{2} \mathrm{~s}\right)$ reference oxidizer mass flux, is reported in Table 4 for all the 


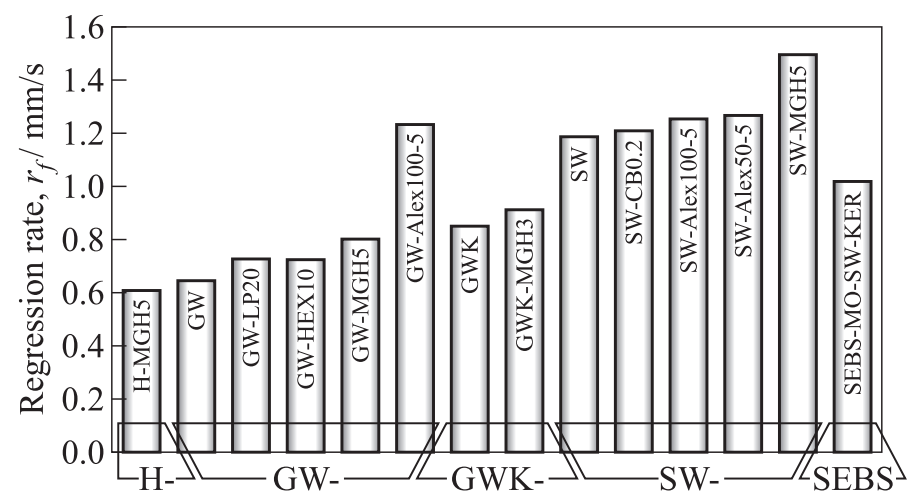

(a)

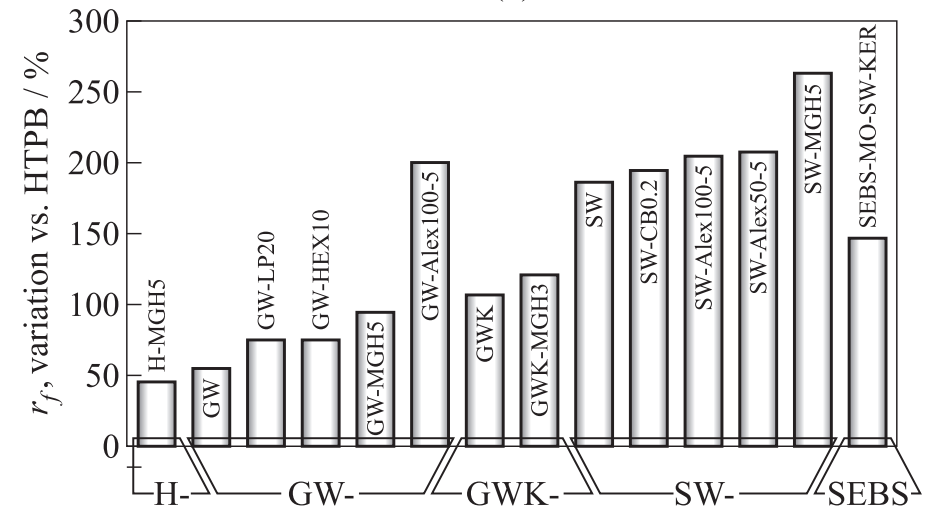

(b)

Figure 10 Regression rate comparison for a selection of the fuel formulations $(a)$ and regression rate percentage compared to pure HTPB for a selection of the fuel formulations $(b)$. Oxygen mass flux $150 \mathrm{~kg} /\left(\mathrm{m}^{2} \mathrm{~s}\right)$; operating pressure $1.5 \mathrm{bar}$

tested formulations, GW-based formulations (see Fig. 10a) allow obtaining $r_{f}$ values higher than those typical of HTPB (up to $+200 \%$ at the selected oxidizer mass flux). The GWK-based formulations (see Fig. 10a) allow obtaining higher performance (up to $+157 \%$ ), the best being those obtained with SW-based fuels (see Fig. $10 a, r_{f}$ up to $+263 \%$ with addition of $\mathrm{MgH}_{2}$, but up to $378 \%$ as reported in Table 4 with addition of $10 \% \mathrm{LAH}$ (not shown in Fig. 10a). The SEBS-based fuel gives an increase of $+148 \%$, thus similar to GWK-based fuels. Results obtained suggest that kerosene addition is effective in enhancing GWbased fuels $r_{f}$, by decreasing their viscosity and thus increasing their tendency to entrainment [13]. A rheological investigation in continuous regime was performed using a Couette Viscosimeter, to investigate the viscosity of the modified 
material. The measured viscosity of GW, GWK, and SW is shown in Table 5 , which reports the values at 60 and $70^{\circ} \mathrm{C}$.

From the data of Table 5, it can be observed that GW displays the higher viscosity values $\left(1.12 \mathrm{~Pa} \cdot \mathrm{s}\right.$ at $\left.70{ }^{\circ} \mathrm{C}\right)$, while SW shows notably lower viscosity $\left(0.09 \mathrm{~Pa}\right.$ at $\left.70{ }^{\circ} \mathrm{C}\right)$. At the same temperature, the viscosity of GWK is one order of magnitude lower than that of pure GW, thus showing the influence of aromaticity on the selected paraffin, as expected from literature analysis.

Table 4 summarizes and extends the results presented in Figs. $10 a$ and $10 b$. The regression rate percentage increase with respect to the reference baseline formulation (pure HTPB) ranges from $47 \%$ for HTPB filled with $\mathrm{MgH}_{2}$ up to $+263 \%$ for $\mathrm{SW}$ filled with $\mathrm{MgH}_{2}$. Intermediate values are obtained for the GWPbased fuels $(56 \%-200 \%)$. The highest regression rate enhancement, under the investigated operating conditions, is obtained with $10 \% \mathrm{LAH}$ addition (up to $+378 \%$ compared to pure HTPB).

When comparing the results obtained for GW-based formulations with those for SW-based formulations, one can notice that GW-based formulations display lower overall regression rate values and higher data dispersion. Moreover, GWbased fuels show the best $r_{f}$ results with $n$-Al addition, while the best $r_{f}$ for SW-based fuels is obtained with the addition of $\mathrm{MgH}_{2}$, which has coarser particle size but higher reactivity when compared to $n$-Al.

The reasons for the observed behavior are due to the fuel higher or lower tendency to entrainment effect, which is determined by the fuel physical properties, in particular, viscosity and surface tension.

The regression rate increase is due to the generation of mass transfer by mechanical means, added to the mass transfer due to the fuel gasification. This extra mass transfer mechanism can significantly increase the regression rate over that of traditional fuels, such as HTPB. Following Karabeyoglu et al. [6, 7, $9]$, in the framework of the linear theory developed for the liquid entrainment modeling, the general empirical expression for the entrainment rate of liquid droplets is:

$$
\dot{m}_{\mathrm{ent}} \propto \frac{p_{d}^{\alpha} h^{\beta}}{\mu^{\gamma} \sigma^{\pi}}
$$

where $\alpha, \beta, \gamma$, and $\pi$ are the empirical coefficients.

An estimation of the entrainment component of mass flux from fuel surface in the present case can be done assuming that the thickness of the melt layer is similar for both GW- and SW-based fuels. Since the measured viscosity of 
SW is one order of magnitude lower than that of GW and SW shows a lower surface tension than GW, the entrainment component of mass flux from fuel surface is higher for SW. This results in a higher entrainment tendency for SWbased fuels. A higher tendency to entrainment effect, in turn, leads to reduced boundary layer blocking effect, reduced particle heat adsorption, and higher particle combustion area. Thus, a higher entrainment tendency globally results in a higher overall regression rate, in a lower particle size effect on $r_{f}$, and in the magnesium hydride reactivity full exploitation, thus explaining the observed results.

\section{CONCLUDING REMARKS}

Some innovative paraffin-based solid fuels for hybrid rocket propulsion were manufactured and tested to investigate their average regression rate increase over that of traditional fuels HTPB-based. Both GW- and SW-based fuels display higher regression rates than those observed for HTPB-based fuels. The best results were obtained for SW fuels (up to $+378 \% r_{f}$ with respect to pure HTPB). Magnesium hydride addition gives better results when added to SW-based fuels, while $n$-Al gives better results when added to GW-based fuels. This trend can be explained taking into account the physical properties of the binders. In particular, the higher or lower tendency to entrainment effects appear to be responsible for the different behavior displayed by GW- and SW-based fuels. The best result was obtained with addition of $\mathrm{LAH}$, which increased the regression rate up to $378 \%$ with 10 percent mass fraction in a SW-based composition.

The research project aimed to develop solid fuels combining at the same time good ballistic and mechanical properties. The kerosene addition was investigated for GW compositions. Kerosene effect can be evaluated comparing GWK and GW formulation: at the reference oxygen mass flux, the regression rate of the GW formulation increases about $56 \%$ compared to the baseline HTPB value, while kerosene addition leads to a regression rate increase about $+107 \%$. The GWK-based formulations allow increasing the regression rate up to $157 \%$ (with 10 percent LAH mass fraction) compared to the reference formulation (pure HTPB).

Two strengthening strategies were investigated: the PUF strengthening and the TPE addition. The PUF reinforced formulations show interesting results, but lead to heterogeneous solid fuels. Homogeneous fuels are obtained with SEBS-containing formulations, allowing isotropic mechanical properties.

The obtained results suggest that further investigation should be dedicated to SW-based fuels added with light metals hydrides, with the aim to upgrade the hybrid engines performance. In particular, the results emphasize the need to investigate in detail the couple binder/additive. Binder and additives properties, 
as well as the additive mass fraction, should be investigated to understand how they change the heat of gasification, the flow-field, and, therefore, the solid fuel regression rate.

\section{ACKNOWLEDGMENTS}

This work has been partially supported by the European Commission, under the ORPHEE project (Operational Research Project on Hybrid Engine in Europe). The research leading to these results has received funding from the European Community's Seventh Framework Programme (FP7/2007-2013) under grant agreement No. 218830.

\section{REFERENCES}

1. Chiaverini, M. J., N. Serin, D. K. Johnson, Y.C. Lu, and G. A. Risha. 2000. Regression rate behavior of hybrid rocket solid fuels. J. Propul. Power. 16(1).

2. Shin, K. H., C. Lee, S. Y. Chang, and J. Y. Koo. 2005. The enhancement of regression rate of hybrid rocket fuel by various methods. AIAA Paper No. 2005-359.

3. Risha, G. A., E. Boyer, R. B. Wehrman, and K. K. Kuo. 2002. Performance comparison of HTPB-based solid fuels containing nano-sized energetic powder in a cylindrical hybrid rocket motor. AIAA Paper No. 2002-3576.

4. Evans, B., N. A. Favorito, E. Boyer, G. A. Risha, R. B. Wehrman, and K. K. Kuo. 2004. Characterization of nano-sized energetic particle enhancement of solid fuel burning rates utilizing a X-ray translucent hybrid rocket motor. AIAA Paper No. 2004-3821.

5. Risha, G. A., B. J. Evans, E. Boyer, and K. K. Kuo. 2006. Metals, energetic additives, and special binders used in solid fuels for hybrid rockets. In: Fundamentals of hybrid rocket combustion and propulsion. Eds. M. J. Chiaverini and K. K. Kuo. Progress in astronautics and aeronautics ser. Reston, VA: AIAA. 185. Ch. 10.

6. Karabeyoglu, M. A., B. J. Cantwell, and D. Altman. 2001. Development and testing of paraffin-based hybrid rocket fuels. AIAA Paper No. 2001-4503.

7. Karabeyoglu, M. A., D. Altman, and B. J. Cantwell. 2002. Combustion of liquefying hybrid propellants: Part 1. General theory. J. Propul. Power 18(3):610-20.

8. Karabeyoglu, M. A., and B. J. Cantwell. 2002. Combustion of liquefying hybrid propellants: Part 2. Stability of liquid films. J. Propul. Power 18(3):621-30.

9. Karabeyoglu, M. A. 2006. Combustion instability and transient behavior in hybrid rocket motors, in fundamentals of hybrid rocket combustion and propulsion. Eds. M. J. Chiaverini and K. K. Kuo. Progress in astronautics and aeronautics ser. Reston, VA: AIAA. 185(Ch. 9).

10. Nakagawa, I., S. Hikone, and T. Suzuki. 2009. A study on the regression rate of paraffin-based hybrid rocket fuels. AIAA Paper No. 2009-4935. 
11. Kim, J. K., and M. A. Paglicawan. 2006. Viscoelastic and gelation studies of SEBS thermoplastic elastomer in different hydrocarbon oils. Macromolecular Res. 14(3):365-72.

12. Kim, S., J. Lee, H. Moon, H. Sung, J. Kim, and J. Cho. 2010. Effect of paraffinLDPE blended fuel in hybrid rocket motor. AIAA Paper No. 2010-7031.

13. Boiocchi, M., L. Merotto, F. Maggi, L. Di Landro, and L. Galfetti. 2011. Rheological and mechanical characterization of hybrid rocket solid fuels. 4th EUCASS (European Conference for Aero-Space Sciences). St. Petersburg, Russia. 